Reviews in Digital Humanities • Vol. 2, No. 6

\title{
Editors' Note: June 2021
}

Roopika Risam $^{1}$, Jennifer Guiliano ${ }^{2}$

${ }^{1}$ Salem State University, ${ }^{2}$ IUPUI

Published on: Jun 14, 2021

DOI: $10.21428 / 3 e 88 f 64 f .75 d 38955$

License: Creative Commons Attribution 4.0 International License (CC-BY 4.0). 
Welcome to the June 2021 issue of Reviews in Digital Humanities!

In addition to managing the workflow that brings you our monthly issues, we've been hard at work with Educopia on long-term planning for the logistical and financial sustainability of Reviews. This has entailed working with Educopia's Katherine Skinner and Brandon Locke to identify stakeholders, look at business models, and imagine future directions for the journal. We're so grateful to the support of Patricia Hswe and the Public Knowledge team at the Andrew W. Mellon Foundation that's making this work possible.

This month, we offer reviews of four projects drawn from our open call for submissions and nominations. Collectively, these projects shed light on the tremendous range of possibilities for scholarly interventions at the intersections of the humanities and technology:

- Against All Odds, a digital archive of the African American men who served in the Mississippi state legislature from Reconstruction until the 1890s, created by DeeDee Baldwin and reviewed by Kimber Thomas;

- Emblem/as, a work of electronic literature exploring personal and geographic cartography, created by Tina Escaja and reviewed by Alex Saum-Pascual;

- RSHHGG Lab, an index for Revue de la société Haïtienne d'histoire, de géographie et de géologie (RSHHGG), directed by Chelsea Stieber and reviewed by Hadassah St. Hubert; and

- GeoMAP, a cartographic project on the history of the Parisian art market, created by Léa Saint-Raymond, Félicie Faizand de Maupeou, and Julien Cavero and reviewed by Kristan M. Hanson.

These projects are linked by a commitment to unearthing stories, histories, and disciplinary perspectives that aren't typically represented in digital humanities scholarship. Our first review, Against All Odds, offers a model of archival reparations by telling the stories of African American men who served in the Mississippi state legislature during Reconstruction and in the two decades that followed. Emblem/as is the first piece of electronic literature to appear in Reviews and articulates the fraught experiences of migration and multilingualism through digital literary art. RSHHGG Lab's transnational, cross-institutional collaboration intervenes in the study of Haiti through journal indexing and annotation-in English, French, and Haitian Kreyòl. Finally, GeoMAP demonstrates the value of digital cultural mapping for art history through its exploration of the late 19th and early 20th century Parisian art market. 
We're also thrilled to share a $\underline{\text { Call for Projects for a special issue on "Race, Medicine, }}$, and Health," guest edited by Kim Gallon (Purdue University) and Kirsten Ostherr (Rice University). The guest editors invite submissions from scholars, artists, communitybased organizations, healthcare professionals, and others who use digital tools and humanities methods to address the intersections of race, medicine, and health, especially those with projects that use digital tools to intervene in or provide resources related to the COVID-19 pandemic. They are particularly interested in projects on COVID-19 and intersecting crises (e.g. racial justice, voter suppression, anti-Asian hate, and white nationalism).

Reviews in Digital Humanities is committed to facilitating peer review for the wide range of digital humanities scholarship being developed. We welcome all methodological approaches and are particularly interested in digital scholarship in Black, Indigenous, Latinx, and Asian studies, as well as projects outside of the U.S. Join our experiment in peer review by submitting a project for review, proposing a special issue, nominating a project you admire, volunteering for our reviewer pool, and telling your colleagues and students about the journal.

Ideas? Questions? Thoughts? Concerns? Contact the editors, Jennifer Guiliano and Roopika Risam, at reviewsindigitalhumanities@gmail.com or through the Twitter hashtag \#ReviewsInDH. 